JIOM Nepal. Volume 41 Number 3. December 2019, page 1-7.

\title{
Implementation of WHO Surgical Safety Checklist and its Outcome in South Asia
}

\section{Göran Kurlberg}

Department of Surgery, The Sahlgrenska Academy, University of Gothenburg, Gothenburg, Sweden

Research Department, Institute of Medicine, Tribhuvan University, Kathmandu, Nepal

\section{Corresponding author:}

\section{Göran Kurlberg, MD, PhD}

Department of Surgery, The Sahlgrenska Academy, University of Gothenburg, Gothenburg, Sweden

Email: goran.kurlberg@surgery.gu.se

Submitted : December 16, 2019

Accepted : December 22, 2019

\begin{abstract}
Introduction

Surgery plays an essential role in any health care system. In 2009, WHO introduced the safe surgery checklist, to improve patient outcome following surgical procedures. The purpose of this trial was to elucidate the effects of the checklist on perioperative complications and checklist implementation at different hospitals in South Asia.
\end{abstract}

\section{Methods}

Online databases were searched to find relevant publications at centres in the South Asian Association for Regional Cooperation (SAARC) area. They were characterised regarding type of study, publication details, study population as well as type of intervention, by the use of the WHO checklist.

\section{Results}

Following the search process, seven full text publications were included in the review. They emanated from five medical centres in India and two from Pakistan. All of these reports found a clear improvement in surgical outcomes and the implementation approached $90-96 \%$.

\section{Conclusion}

The WHO checklist is a valuable tool to reduce surgical complications, especially in resource-limited settings, where it should be more commonly used.

Keywords: Checklist, complications, SAARC, safe surgery

\section{INTRODUCTION}

n 2015 the Lancet Commission on Global Surgery was launched as a public health initiative to enhance surgery, obstetric, anaesthesia care worldwide. The Commission's key findings reveal that human and economic consequences of unmet surgical needs in low- and middleincome countries are substantial and five billion people lack access to safe, affordable and timely surgical and anaesthesia care when needed. Thus, surgery plays an essential role in any health care system and globally an estimated 234 million surgical procedures are performed every year. Of these surgeries around seven million end up with different complications and one million patients die every year. ${ }^{1-3}$ A majority of these adverse events occur in the operating room and $43 \%$ of these mishaps are preventable by modern standards of care. $^{4}$

Prior to the introduction of the Lancet Commission on Global Surgery the World Health Organisation developed guidelines to identify practices to ensure the safety of surgical procedures worldwide. With experience from the aviation industry, where interventions focus on teamwork and safety climate, WHO introduced a 19-item 
surgical safety checklist, in 2009, directed towards these parameters to improve patient outcome following surgical procedures. ${ }^{5}$ In an international multicentre study including 8 hospitals from different countries, the implementation of this checklist brought about a significant reduction in postoperative complications and mortality. ${ }^{5}$ The checklist is used during three different time-points of any surgical procedure. Before anaesthesia is administered, the patient identity, site, procedure and consent, as well as equipment, medication and allergy are checked (sign in). Immediately before incision, name of patient, team members, procedure and incision, as well as control of antibiotic- and thromboprophylaxis, radiographs and anticipated critical events are controlled (time out). Prior to the patient is leaving the OR, equipment problems are notified as well as any key concerns for the recovery (sign out). ${ }^{6,7}$ The checklist is intended to give surgical teams a simple and efficient set of priority checks to ensure patient safety, by effective teamwork and enhanced communication between team members in every operation performed.

Although the awareness of the benefits using the checklist is universal its implementation is lagging behind especially in many low- and midincome countries (LMICs). ${ }^{8}$ From previous studies it is evident that applying the checklist in resourcelimited settings is particularly relevant to improve surgical care and outcome. ${ }^{5,8}$ In order to elucidate the use of the WHO surgical safety checklist in LMICs, in the Asian context, the present review study was performed. Links were sought between implementation of checklist practice and different outcomes involving centres from countries in the South Asian Association of Regional Cooperation.

\section{AIM}

The purpose of this trial was to analyze

- Effects of WHO surgical safety checklist implementation on perioperative mortality and complications

- Checklist compliance rates following implementation in resource-limited settings

\section{METHODS}

A search for relevant publications was carried out. The online databases PubMed and SCOPUS were searched using the term "safe surgery checklist". Studies were limited to those written in English language, and including abstracts. Initially all abstracts found were read with the intention to find publications of trials performed in SAARC countries: Afghanistan, Bangladesh, Bhutan, India,

\author{
Initial literature search - 163 items \\ $\downarrow$ \\ Removed non-English and \\ no abstract papers - 45 items \\ $\downarrow$ \\ Papers selected for \\ title/abstract screening - 118 items \\ $\downarrow$ \\ Potentially relevant \\ full text papers retrieved - 10 items
}

$\downarrow$

Removed non-relevant, non-SAARC papers - 3 items

$\downarrow$

Included studies - 7 items

Figure 1. Search strategy of PubMed and Scopus, process and results

Maldives, Nepal, Pakistan and Sri Lanka.

The studies were characterised regarding type of study, publication details, study population and hospital setting, as well as intervention (Table 1). The 19-item WHO surgical safety checklist (SSC) is added as an appendix.

In four of the papers "no conflict of interest" was declared and ethical approval had been granted in the same amount of publications.

\section{RESULTS}

The search process identified 163 papers, of which 45 were removed because of non-English texts and lack of abstracts. Remaining 118 items went for title and/or abstract screening. Ten papers were identified for their potential relevance and selected for full text review. Three items were excluded due to irrelevance or researched from centres outside South Asia. Thus, seven publications were included in the review process (Fig 1).

The papers involved in this review were from five centres in India and two institutions in Pakistan. Altogether 9119 patients and 669 healthcare personnel were involved in the different trials. Four of the studies elucidated the WHO safe surgery checklist influence on postoperative mortality and complications. All of these reports found a clear improvement in surgical outcomes after the introduction of the checklist. Three of these studies also researched the checklist implementation and completion; after a period of introduction the completion of implementation approached $90-96 \%$. The SSC was found easy to use, and 


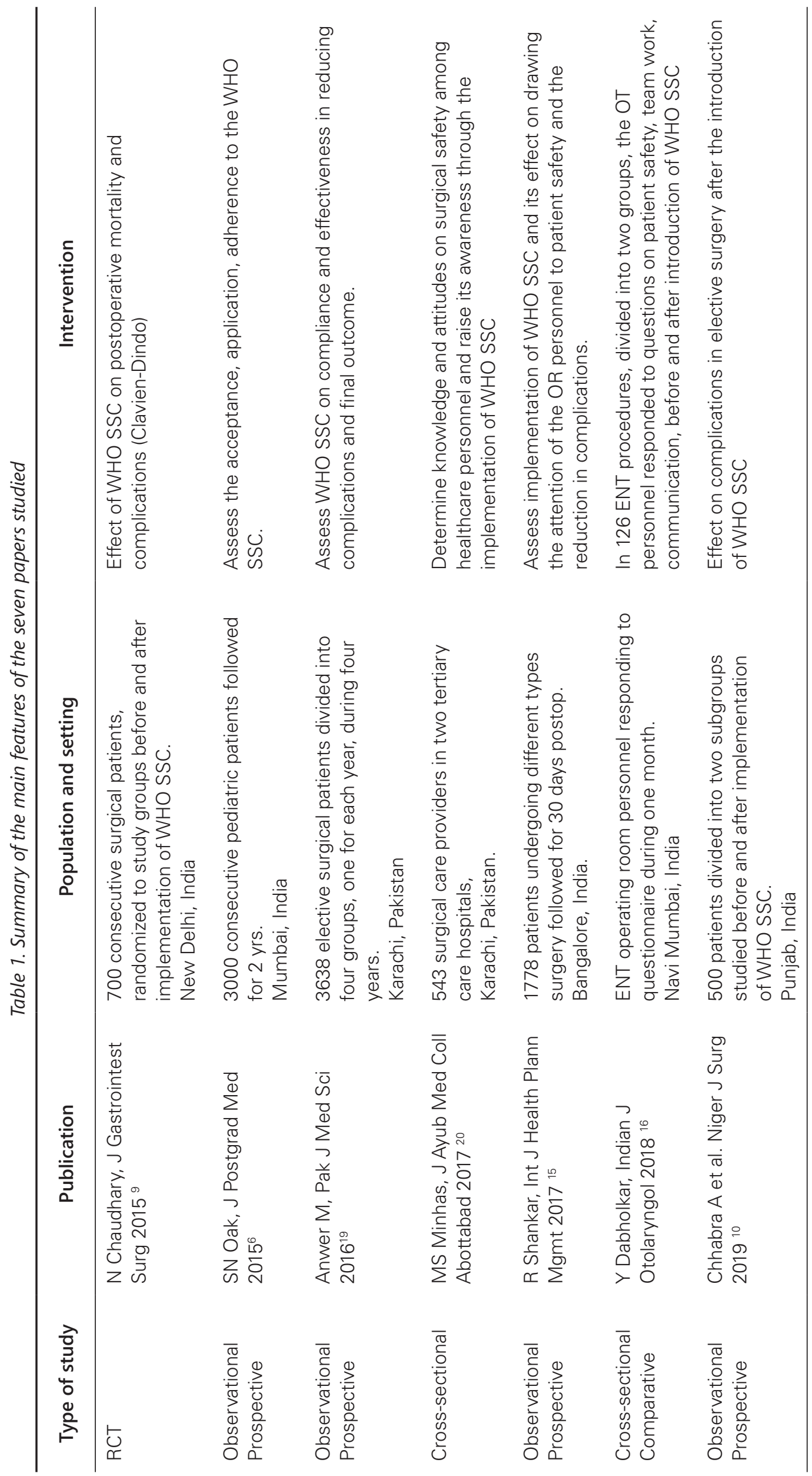


Table 2. Summary of study results on reduction of complications after introduction of the surgical safety checklist

\begin{tabular}{|c|c|c|}
\hline Study & Outcome & Checklist \\
\hline $\begin{array}{l}\text { N Chaudhary, } \\
\text { J Gastrointest } \\
\text { Surg } 2015\end{array}$ & $\begin{array}{l}\text { Differencespre/post SSC in } 340 / 280 \text { complications. } \\
\text { No differences in preoperative values or hospital } \\
\text { stay. Wound complications } 8.5 \%-4.5 \%, p=0.04 \text {, } \\
\text { abdominal } 28 \%-19.7 \%, p=0.01 \text {, bleeding } 2.8 \%- \\
0.5 \%, p=0.03 \text {. Mortality } 10 \%-5.7 \%, p=0.04 \text {. No } \\
\text { differences in terms of respiratory, septic, renal } \\
\text { and cardiovascular complications }\end{array}$ & Checklist compliance $85 \%$ \\
\hline $\begin{array}{l}\text { Anwer M, Pak } \\
\text { J Med Sci } \\
2016\end{array}$ & $\begin{array}{l}\text { Surgical site infections occurred in } 59(7.5 \%), 52 \\
(6.4 \%), 44(4.7 \%), 20(2.1 \%) \text { of the cases for } \\
1 \text { st, 2nd, 3rd, 4th year. No difference in chest } \\
\text { complications or mortality. }\end{array}$ & $\begin{array}{l}\text { In } 1 \text { st year SSC was properly marked in } \\
172 / 840 \text { cases }(20.4 \%) \text {, 2nd year } 303 \text { of } \\
857 \text { cases }(35.3 \%) \text {, 3rd year } 757 \text { of } 935 \\
\text { procedures }(80.9 \%) \text {, and } 4 \text { th year } 838 \\
\text { of } 932 \text { cases }(89.9 \%) \text {. No significant } \\
\text { mishaps on site/side. }\end{array}$ \\
\hline $\begin{array}{l}\text { R Shankar, Int } \\
\text { J Health } \\
\text { Plann Mgmt } \\
2017\end{array}$ & $\begin{array}{l}1778 \text { patients were studied during introduction of } \\
\text { SSC. Data collection during } 30 d \text { for each patient } \\
\text { in nine weeks study. } 73 \text { complications during } \\
\text { the period }(4.1 \%) \text { of these } 44 \text { were surgical site } \\
\text { infections, after } 100 \% \text { prophylactic antibiotics. }\end{array}$ & $\begin{array}{l}43 \text { errors detected and corrected on } \\
\text { checklist }\end{array}$ \\
\hline $\begin{array}{l}\text { Chhabra A } \\
\text { et al. Niger J } \\
\text { Surg } 2019\end{array}$ & $\begin{array}{l}\text { After an information phase the introduction of } \\
\text { the SSC decreased the frequency of surgical site } \\
\text { infections from } 73 \text { cases }(29.2 \%) \text {. to } 34(13.6 \%) \\
\text { p<0.05, major wound disruptions } 27 \text { pts before } \\
(10.8 \%) 13 \text { pts after SSC }(5.2 \%) p<0.05,5 \text { pts } \\
(2 \%) \text { preSSC developed sepsis but none after } \\
\text { introduction of the checklist } p<0.05 \text {. No significant } \\
\text { differences in other complications. }\end{array}$ & Implementation differences not studied \\
\hline
\end{tabular}

through the use of SSC errors could be detected and corrected (Table 2)

Another three studies focused on the implementation of the WHO surgical safety checklist and its role on postoperative outcome improvement. One study found that although operation room personnel largely reject established protocols, the implementation of the WHO SSC was accepted for use. Also in these reports the checklist completion rate was, more than 90\%; errors were detected and corrected. The checklist implementation also scored high on improved OR team communication and thus patient safety (Table 3).

\section{DISCUSSION}

In this review study on the implementation of the WHO surgical safety checklist (SSC) in some resource-limited centres in the South Asian region seven papers from India and Pakistan were included. The four studies focusing on postoperative patient outcomes, propose a reduction in complications after the implementation of the checklist. The implementation of the checklist was also successful in the settings were this was studied.

The reduction in advert events following the implementation of the WHO checklist was mainly seen in surgical complications, like less surgical site infections (SSI), wound disruption, bleeding. Decline in mortality was seen in one reviewed paper, ${ }^{9}$ but elsewise the death rate was not obvious. One study found less sepsis events post checklist implementation, ${ }^{10}$ otherwise no differences in other medical complications, like renal failure, myocardial infarction, etc. after the introduction of the SSC. These are probably 
Table 3. Summary of studies on surgical safety checklist (SSC) after implementation

\begin{tabular}{|c|c|c|}
\hline Study & Outcome & Checklist \\
\hline $\begin{array}{l}\text { SN Oak, J Postgrad } \\
\text { Med } 2105\end{array}$ & $\begin{array}{l}\text { Out of } 3000 \text { paediatric procedures, the } \\
\text { SSC detected: } 54 \text { pts with same name and } \\
\text { procedure, } 4 \text { pts' ID tag missing, } 108 \text { pts no } \\
\text { side/site marked, } 78 \text { pts consent form not } \\
\text { signed, } 4 \text { pts antibiotics not given, 12pts not } \\
\text { properly immobilised. }\end{array}$ & $\begin{array}{l}\text { In } 54 \text { cases checklist not used, } 76 \\
\text { incompletely filled out }\end{array}$ \\
\hline $\begin{array}{l}\text { MS Minhas, J Ayub } \\
\text { Med Coll Abottabad } \\
2017\end{array}$ & $\begin{array}{l}543 \text { health care providers (surgeons, } \\
\text { anaesthetists, trainees, nurses) took part in } \\
\text { the study. } 69 \% \text { were men with mean age of } \\
40.5 \text { years. Briefing OR personnel for patient } \\
\text { safety was regarded important by } 98 \% \text {, team } \\
\text { communication by } 89 \% \text { of responders. OR } \\
\text { personnel frequently disregarded protocols in } \\
69 \% \text { and } 193,(35.5 \% \text { ) thought it was difficult } \\
\text { to speak up in the OR. }\end{array}$ & $\begin{array}{l}80 \% \text { of the responders agreed that } \\
\text { the WHO SSC would be easy to } \\
\text { use, improve team communication } \\
(89 \%) \text {, prevent errors (93.5\%), } \\
\text { improve OR safety }(91.5 \%) \text {. }\end{array}$ \\
\hline $\begin{array}{l}\text { Y Dabholkar, Indian J } \\
\text { Otolaryngol } 2018\end{array}$ & - & $\begin{array}{l}\text { After introduction of SSC team } \\
\text { members increased the awareness } \\
\text { of patient identity from } 17 \text { to } 86 \% \text {, } \\
\text { each others identity and roles from } \\
46 \text { to } 94 \% \text {, radiographs displayed } \\
\text { from } 19 \text { to } 98 \% \text {, equipment } \\
\text { issues addressed from } 41 \text { to } \\
81 \% \text { and improved effective team } \\
\text { communication from } 73 \text { to } 92 \% \text {. }\end{array}$ \\
\hline
\end{tabular}

Y Dabholkar, Indian J -

Otolaryngol 2018

more due to the patient's general condition and comorbidities. de Vries et al in a multi-centre study of 3820 cases in the Netherlands, found following implementation of the WHO checklist a moderate reduction in surgical complications and mortality compared to the control setting. ${ }^{11}$ However, as seen in the GlobalSurg Collaborative study reduction in complications in this high-income setting was less pronounced than in resource limited countries. ${ }^{8}$

The mechanisms behind the improved surgical outcome following implementation of the checklist are not well understood, but is probably due multiple factors. Strict adherence to protocols of antibiotic prophylaxis could contribute to less SSI, but also improved hygiene, and atraumatic surgery. ${ }^{12,13}$ A decrease in number of wound dehiscence's could also be explained by greater adherence to the principle of suture and incision length ratio not scoring less than 4 , as advocated by Israelsson et al. ${ }^{14}$

Adherence to the WHO SSC protocol was in general high after proper introduction and training in the practice of the checklist. Implementation and completion of the checklist changed the working climate in the operating rooms studied. The checklist was regarded easy to use among the centres involved in the review. Team work and communication improved considerably between surgeons, anaesthetists, nurses and technicians, changing attitudes, preventing errors and strengthen safety in the OR. ${ }^{15,16}$

However, in a resource-limited area of 1.8 billion people only seven publications were found studying the use and impact of the WHO safe surgery checklist. There may be many more hospitals using the checklist without publishing its implementation and their experiences of the outcome. Barriers to implementation of the SSC in South Asia could possibly be explained by different sociocultural and organisational patterns. Hospitals in this area are still affected by hierarchical structures among OR personnel. ${ }^{17}$ This is the more remarkable since hospitals in LMIC seem to benefit the most from using the WHO safe surgery checklist. In 


\section{Surgical Safety Checklist}

\begin{tabular}{|c|c|c|}
\hline Before induction of anaesthesia & Before skin incision & Before patient leaves operating room \\
\hline (with at least nurse and anaesthetist) & (with nurse, anaesthetist and surgeon) & \multirow{6}{*}{$\begin{array}{l}\text { (with nurse, anaesthetist and surgeon) } \\
\text { Nurse Verbally Confirms: } \\
\square \text { The name of the procedure } \\
\square \text { Completion of instrument, sponge and needle } \\
\text { counts } \\
\square \text { Specimen labelling (read specimen labels aloud, } \\
\text { including patient name) } \\
\square \text { Whether there are any equipment problems to be } \\
\text { addressed }\end{array}$} \\
\hline $\begin{array}{l}\text { Has the patient confirmed his/her identity, } \\
\text { site, procedure, and consent? }\end{array}$ & $\begin{array}{l}\square \text { Confirm all team members have } \\
\text { introduced themselves by name and role. }\end{array}$ & \\
\hline$\square$ Yes & $\square$ Confirm the patient's name, procedure, & \\
\hline Is the site marked? & & \\
\hline$\square$ Yes & \multirow{3}{*}{$\begin{array}{l}\text { Has antibiotic prophylaxis been given within } \\
\text { the last } 60 \text { minutes? } \\
\square \text { Yes } \\
\square \text { Not applicable }\end{array}$} & \\
\hline$\square$ Not applicable & & \\
\hline $\begin{array}{l}\text { check complete? } \\
\text { chestion }\end{array}$ & & \multirow{13}{*}{$\begin{array}{l}\text { To Surgeon, Anaesthetist and Nurse: } \\
\square \text { What are the key concerns for recovery and } \\
\text { management of this patient? }\end{array}$} \\
\hline$\square$ Yes & \multirow{4}{*}{$\begin{array}{l}\text { Anticipated Critical Events } \\
\text { To Surgeon: } \\
\square \text { What are the critical or non-routine steps? } \\
\square \text { How long will the case take? } \\
\square \text { What is the anticipated blood loss? }\end{array}$} & \\
\hline $\begin{array}{l}\text { Is the pulse oximeter on the patient and } \\
\text { functioning? } \\
\square \text { Yes }\end{array}$ & & \\
\hline$x^{2}$ & & \\
\hline Does the patient have a: & & \\
\hline Known allergy? & \multirow{3}{*}{$\begin{array}{l}\text { To Anaesthetist: } \\
\square \text { Are there any patient-specific concerns? } \\
\text { To Nursing Team: }\end{array}$} & \\
\hline$\square$ No & & \\
\hline$\square$ Yes & & \\
\hline $\begin{array}{l}\text { Difficult airway or aspiration risk? } \\
\square \text { No }\end{array}$ & \multirow{2}{*}{$\begin{array}{l}\square \text { Has sterility (including indicator results) } \\
\text { been confirmed? } \\
\square \text { Are there equipment issues or any concerns? }\end{array}$} & \\
\hline$\square$ Yes, and equipment/assistance available & & \\
\hline Risk of $>500 \mathrm{ml}$ blood loss $(7 \mathrm{ml} / \mathrm{kg}$ in children)? & \multirow{3}{*}{$\begin{array}{l}\text { Is essential imaging displayed? } \\
\square \text { Yes } \\
\square \text { Not applicable }\end{array}$} & \\
\hline$\square$ No & & \\
\hline $\begin{array}{l}\square \text { Yes, and two IVs/central access and fluids } \\
\text { planned }\end{array}$ & & \\
\hline
\end{tabular}

This checklist is not intended to be comprehensive. Additions and modifications to fit local practice are encouraged.

two multinational trials the checklist use in $\mathrm{HIC}$ was double that of low-income countries, but the greatest benefits from checklist use were found in emergency surgery in low- and middle-income countries. $^{8}$ Ethiopia could stand out as a model for low-income countries. The Federal Ministry of Health recognizing the unmet need for surgery and pioneered the Saving Lives Safe Surgery initiative. In eight different areas also including the implementation of the WHO safe surgery checklist has seen transformation in health care including improved surgical outcomes. ${ }^{18}$ Ethiopia seems to be an example for other resource limited countries, in overcoming the barriers towards implementation of SSC use by enthusiastic leadership, development of appropriate strategies and training programs in implementing the $\mathrm{WHO}$ safe surgery checklist.

\section{CONCLUSION}

The World Health Organisation surgical safety checklist was in this review study from seven medical centres in the SAARC area noticed to be a promising protocol, easy to implement and use in any operation theatre given an enthusiastic leadership. The checklist was found to reduce surgical complications, but not to the same extent the postoperative mortality. Given the vast South Asian area reviewed the limited number of hospitals reporting their experiences of the checklist is highly remarkable. There is certainly room for expansion in use of this valuable tool to fight surgical complications, especially in lowresource settings.

\section{CONFLICT OF INTEREST}

None declared.

\section{REFERENCES}

1. Meara JG, Leather AJ, Hagander L, Alkire BC, Alonso N, Ameh EA, et al. Global Surgery 2030: evidence and solutions for achieving health, welfare, and economic development. Lancet (London, England). 2015;386(9993):569-624.

2. Wilson I, Walker I. The WHO Surgical Safety Checklist: the evidence. Journal of perioperative practice. 2009;19(10):362-4.

3. Jones S. Your life in WHOs hands: the World Health Organization Surgical Safety Checklist: a critical review of the literature. Journal of perioperative practice. 2011;21(8):271-4.

4. de Vries EN, Ramrattan MA, Smorenburg SM, Gouma DJ, Boermeester MA. The incidence and nature of in-hospital adverse events: a systematic review. Quality \& safety in health care. 
$2008 ; 17(3): 216-23$.

5. Haynes AB, Weiser TG, Berry WR, Lipsitz SR, Breizat $A H$, Dellinger $E P$, et al. A surgical safety checklist to reduce morbidity and mortality in a global population. The New England journal of medicine. 2009;360(5):491-9.

6. Oak SN, Dave NM, Garasia MB, Parelkar SV. Surgical checklist application and its impact on patient safety in pediatric surgery. Journal of postgraduate medicine. 2015;61(2):92-4.

7. Weiser TG, Haynes AB, Dziekan G, Berry WR, Lipsitz SR, Gawande AA. Effect of a 19-item surgical safety checklist during urgent operations in a global patient population. Annals of surgery. 2010;251(5):976-80.

8. Pooled analysis of WHO Surgical Safety Checklist use and mortality after emergency laparotomy. The British journal of surgery. 2019;106(2):e103-e12.

9. Chaudhary $N$, Varma V, Kapoor S, Mehta N, Kumaran V, Nundy S. Implementation of a surgical safety checklist and postoperative outcomes: a prospective randomized controlled study. Journal of gastrointestinal surgery : official journal of the Society for Surgery of the Alimentary Tract. 2015;19(5):935-42.

10. Chhabra A, Singh A, Kuka PS, Kaur H, Kuka AS, Chahal H. Role of Perioperative Surgical Safety Checklist in Reducing Morbidity and Mortality among Patients: An Observational Study. Nigerian journal of surgery : official publication of the Nigerian Surgical Research Society. 2019;25(2):192-7.

11. de Vries EN, Prins HA, Crolla RM, den Outer AJ, van Andel G, van Helden SH, et al. Effect of a comprehensive surgical safety system on patient outcomes. The New England journal of medicine. 2010;363(20):1928-37.

12. Haynes AB, Weiser TG, Berry WR, Lipsitz SR, Breizat $A H$, Dellinger EP, et al. Changes in safety attitude and relationship to decreased postoperative morbidity and mortality following implementation of a checklist-based surgical safety intervention. BMJ quality \& safety. 2011;20(1):102-7.

13. Tang $R$, Ranmuthugala $G$, Cunningham F. Surgical safety checklists: a review. ANZ journal of surgery. 2014;84(3):148-54.

14. Israelsson LA, Millbourn D. Prevention of incisional hernias: how to close a midline incision. The Surgical clinics of North America. 2013;93(5):102740.

15. Shankar R. Implementation of the WHO Surgical Safety Checklist at a teaching hospital in India and evaluation of the effects on perioperative complications. The International journal of health planning and management. 2018;33(4):836-46.

16. Dabholkar $Y$, Velankar $H$, Suryanarayan $S$, Dabholkar TY, Saberwal AA, Verma B. Evaluation and Customization of WHO Safety Checklist for Patient Safety in Otorhinolaryngology. Indian journal of otolaryngology and head and neck surgery : official publication of the Association of Otolaryngologists of India. 2018;70(1):149-55.

17. Jain $D$, Sharma R, Reddy $S$. WHO safe surgery checklist: Barriers to universal acceptance. Journal of anaesthesiology, clinical pharmacology. 2018;34(1):7-10.

18. Burssa D, Teshome A, Iverson $K$, Ahearn $O$, Ashengo T, Barash $D$, et al. Safe Surgery for All: Early Lessons from Implementing a National Government-Driven Surgical Plan in Ethiopia. World journal of surgery. 2017;41(12):3038-45.

19. Anwer M, Manzoor S, Muneer N, Qureshi S. Compliance and Effectiveness of WHO Surgical Safety Check list: A JPMC Audit. Pakistan journal of medical sciences. 2016;32(4):831-5.

20. Minhas MS, Muzzammil M, Effendi J. Assessment Of Safety Levels In Operation Rooms At Two Major Tertiary Care Public Hospitals Of Karachi. "Safe Surgery Saves Life". Journal of Ayub Medical College, Abbottabad: JAMC. 2017;29(4):580-6. 